\title{
Surface Hydrophobicity Properties of Rabbit Stomach In Vitro
}

\author{
DAVID R. MACK,' A. WILHELM NEUMANN, ZDENKA POLICOVA. AND PHILIP M. SHERMAN \\ Division of Gastroenterology: Research Institute, The Hospital for Sick Children. Departments of Pediatrics \\ [D. R.M., P.M.S.J, Mechanical Engineering [A.U.N., Z.P.J. and Microbiology. P.M.S./. Lniversity of Toronto, \\ Toronto, Ontario, Canada
}

\begin{abstract}
To quantitate surface hydrophobicity of the stomach, we measured contact angles formed with water droplets in different regions of rabbit stomach at varying ages (suckling, weanling, and adult). Contact angles were measured using novel methods: axisymmetric drop-shape analysis-contact diameter for contact angles $<90^{\circ}$ and axisymmetric drop-shape analysis-maximum diameter for contact angles $>90^{\circ}$. To determine whether gastric mucus was responsible for the physical properties of the surface mucosa, the surface tension of mucus derived from the body of stomach was measured by axisymmetric dropshape analysis on pendant drops. Contact angles of adult antrum $82.9^{\circ} \pm 5.5^{\circ}$ (mean $\pm \mathrm{SEM}$ ) were greater than in the body of stomach $\left(36.1^{\circ} \pm 2.6^{\circ}, p=0.0001\right)$. Contact angles on mucosa obtained from the body of the stomach of both suckling rabbits $\left(76.4^{\circ} \pm 2.7^{\circ}\right)$ and weanling rabbits $\left(84.2^{\circ} \pm 2.9^{\circ}\right.$ ) were greater than in adult animals (ANOVA, $p<0.05)$. Pendant drop analysis of mucus derived from the body of stomach showed a high surface tension $(57.72$ $\pm 0.06 \mathrm{~mJ} / \mathrm{m}^{2}$, mean \pm SD). We conclude that there are maturational changes and regional differences in the surface hydrophobicity of the lapine stomach. These changes are likely caused by changes in the overlying mucus layer. (Pediatr Res 35: 209-213, 1994)
\end{abstract}

\section{Abbreviations}

ADSA, axisymmetric drop-shape analysis ADSA-CD, ADSA-contact diameter ADSA-P, ADSA pendant drop ADSA-MD, ADSA-maximum diameter ANOVA, analysis of variance

Bacterial adhesion to mucosal surfaces is recognized as a virulence factor for microbial pathogens because it promotes delivery of toxins and it is a prerequisite for invasion into eukaryotic cells (1). Both specific ligand-receptor interactions and nonspecific surface properties, including charge and hydrophobicity, promote binding of microbial pathogens to mucosal surfaces $(2,3)$.

In a previous study, we showed regional differences in the surface hydrophobicity of lapine small bowel and colon that were

Received April 8, 1993; accepted September 30, 1993.

Correspondence and reprint requests: P. M. Sherman. M.D., F.R.C.P.(C.) Division of Gastroenterology (Room 1448). The Hospital for Sick Children. 555 University Ave., Toronto, Ontario M5G 1X8. Canada.

Supported by grants from the Medical Research Council of Canada. D.R.M. was the recipient of a Duncan Gordon Research Fellowship from The Hospital for Sick Children Foundation. P.M.S. is the recipient of a Career Scientist Award from the Ontario Ministry of Health.

'Present address: University of Nebraska Medical Center, Omaha, NE. related to the surface tension of the mucus layer overlying surface epithelial cells (4). In addition, changes in surface hydrophobicity were related to the stage of the rabbits' postnatal development. Although the stomach has been previously considered relatively sterile, it is now clear that certain gram-negative, microaerobic bacteria demonstrate tropism for the gastric microenvironment. For example. Helicobacter py/ori fulfills each of Koch's postulates as a human pathogen causing chronic-active gastritis (5). $H$. pylori colonization of the stomach has also been associated with recurrent peptic ulceration (6) and the development of gastric cancers (7). This gastric pathogen inhibits acid secretion ( 8 ) but stimulates pepsinogen secretion (9) in suspensions of lapine parietal cells. The factors mediating colonization and adhesion of $H$. pylori to gastric surfaces are not known. However, when compared with noninfected, age-matched controls, reduced hydrophobicity is evident on stomach mucosal surfaces obtained using endoscopic biopsies from $H$. py/ori-infected individuals $(10-12)$. In the present study, we examined surface hydrophobicity in the body and antrum of rabbit stomach at varying ages after birth.

\section{MATERIALS AND METHODS}

Preparation of stomach sections for contact angle measurements. New Zealand White rabbits (Reimans Fur Ranch, Guelph, Canada) were used for all experiments. The research protocol was reviewed and approved by the hospital's Animal Care Committee. Nine suckling rabbits were examined at $2 \mathrm{wk}$ of age, three weanling rabbits (littermates) were examined at 6 wk of age (body weight $=0.8 \mathrm{~kg}$ ), and three male postweanling rabbits between 3 and 4 mo of age weighing approximately $3 \mathrm{~kg}$ were studied. Animals were killed using intracardiac Euthanyl (MTC Pharmaceuticals, Cambridge, Canada) after anesthesia with intramuscular ketamine (Parke-Davis, Scarborough, Canada) and xylazine (Bayvet. Etobicoke. Canada). A midline abdominal incision was then made to open the peritoneal cavity and the entire stomach was excised. Segments from antrum (2 $\left.\mathrm{cm}^{2}\right)$ and body of the stomach $\left(9 \mathrm{~cm}^{2}\right)$ were washed with sterile saline at $4^{\circ} \mathrm{C}$ and mounted onto a flat surface of dental wax. Water droplets did not form on freshly isolated stomach mucosal surfaces. Therefore, stomach segments were allowed to air dry at room temperature and were constantly watched until the mucosa developed a dull, matted appearance, as previously described (4. 10-12).

Preparation of mucus. Mucus is a complex mixture of mucin glycoproteins, water, various serum and cellular macromolecules, electrolytes, microorganisms, and sloughed epithelial cells (13). Soluble mucus was prepared from the mucosa of the body of the stomach of adult rabbits, as described previously $(14,15)$. Briefly, excised sections were opened and washed with sterile saline at $4^{\circ} \mathrm{C}$. Mucosal tissue was obtained by gently scraping the luminal surface with a glass slide. Scrapings were weighed and placed into a solution of $5 \mathrm{mM}$ EDTA $(100 \mathrm{~mL} / \mathrm{g}$ wet weight; Sigma 
Chemical Co., St. Louis, MO) containing $0.01 \%$ sodium azide (Sigma) and proteinase inhibitors to minimize the proteolytic degradation of mucins (15). The proteinase inhibitors contained $5 \mathrm{mM} \mathrm{N}$-ethylmaleimide (Sigma) and $2 \mathrm{mM}$ phenylmethyl sulfonyl fluoride (Sigma). Scrapings of the mucosa were then homogenized in a blender for $30 \mathrm{~s}$. The homogenate was centrifuged at $30000 \times g$ for $30 \mathrm{~min}$ at $4^{\circ} \mathrm{C}$ to remove pelleted cellular and particulate debris. Protein content of the soluble preparations was determined by the method of Lowry et al. (16) using BSA (Sigma) as the reference standard. The soluble supernatants, defined as crude mucus, were then stored at $-70^{\circ} \mathrm{C}$ until further use in the pendant drop-shape analyis.

Measurement of hydrophobicity of intestinal mucosal surfaces. The technique for measurement of contact angles, referred to as ADSA-CD, was performed as described in detail previously (17, 18). This method calculates contact angles by solving the Laplace equation using liquid surface tension. drop volume, and the contact diameter of a water droplet as input parameters. Sessile drops of distilled water were placed onto air-dried stomach mucosal surfaces. The volume of the drops of water was obtained by using a micrometer syringe (Gilmont, Canlab, Toronto, Canada). Surface tension of the water droplet was determined using the Wilhelmy technique (19). Contact diameter of the drop of water was determined by computer digitization of an advancing droplet periphery on an image taken from above $(4,20)$. The image was obtained, using a stereomicroscope (M7S Zoom. Wild Heerbrugg, Germany), within $1 \mathrm{~s}$ after the water droplet formed on the surfaces of gastric mucosa.

ADSA-CD was developed initially from the more general ADSA-P (see below) for the purpose of determining small contact angles, which cannot be determined with a high degree of accuracy by means of ADSA-P. ADSA-CD has proven to be an excellent tool for the determination of contact angles when the solid substrata are rough and heterogeneous, thereby producing sessile drops with ragged three-phase lines rather than circular ones $(21,22)$. In the course of previous investigations, we encountered situations in which the contact angle was greater than $90^{\circ}$ so that the contact area could not be seen by observation of the sessile drops from above (4). Rather, this observation records the maximum equatorial diameter of such drops. To avoid losing the power of ADSA-CD to average irregularities of the threephase line, a further modification of ADSA called ADSA-MD was developed (23). In this technique, the maximum equatorial diameter is determined using the same experimental apparatus with which ADSA-CD measurements are performed. The required input also remains unchanged: surface tension and density of the liquid, drop volume, and local gravity. The main output quantity is the average effective contact angle of the water droplet. Thus, in the present experiments. contact angles less than $90^{\circ}$ were determined using ADSA-CD and those greater than $90^{\circ}$ by ADSA-MD.

Measurement of surface tension of soluble mucus. The crude mucus preparations were measured at a concentration of $1 \mathrm{mg} /$ $\mathrm{mL}$. Surface tension values of the crude mucus were obtained by means of ADSA-P using pendant drops (4). This technique calculates the surface tension by fitting the Laplace equation of capillarity to an arbitrary array of coordinate points selected from the drop profile. The profile coordinates were found and analyzed by an automatic digitization technique described in detail previously $(21,22)$. Briefly, the pendant drop was formed inside a quartz cuvette at the tip of a Teflon capillary that was inserted into a stainless steel tube to keep the capillary straight. To maintain vapor pressure in equilibrium and to prevent evaporation of the pendant drop during the time of the experiment, the cuvette was half filled with the sample of mucus and then sealed. The measurements were performed at room temperature. In addition to the drop profile coordinates, the analysis required only information on the local gravity and density of the liquid. Density of the mucus preparations $\left(1 \mathrm{mg} / \mathrm{mL}\right.$ ) was $999.9 \mathrm{~kg} / \mathrm{m}^{3}$, as determined using a digital densitometer (Digital Meter, DMA 45. Anton Paar, Graz, Austria).

Statistics. Results are expressed as means \pm SEM for the number of droplets tested unless otherwise indicated. Comparisons between the two regions of the stomach were made by unpaired, two-tailed $t$ test (24). Comparisons between multiple groups were determined using Fisher protected least-significant difference one-factor ANOVA at $95 \%$ confidence intervals (24).

\section{RESULTS}

Regional differences in hydrophobicity: For these experiments. 24 drops were formed on antral tissue and 25 drops on tissue derived from the body of stomach for determination of contact angles by ADSA-CD in the three animals evaluated. Comparisons were performed on the number of drops formed because we showed previously that an evaluation of contact angles is the same when comparisons are made for either the number of drops or the averages for drops formed with each animal (4). As shown in Figure 1, contact angles formed on the antrum $\left(82.9^{\circ} \pm 5.5 \%\right.$. mean $\pm \mathrm{SEM}$ ) of adult rabbits were significantly greater than those formed on the mucosa from the body of stomach $\left(36.1^{\circ} \pm\right.$ $2.6^{\circ}, p=0.0001$ ).

Ontogeny of surface hydrophobicity: There was no regional variation in surface hydrophobicity within the stomach of suckling rabbits. The contact angles formed by water droplets on the body of stomach $\left(76.4^{\circ} \pm 2.2^{\circ}, n=48\right)$ were comparable to those on antral mucosa $\left(76.8^{\circ} \pm 6.1^{\circ}, n=23, p>0.05\right)$. In weanling rabbits, both regions of the stomach were hydrophobic in nature with contact angles in the body $\left(84.2^{\circ} \pm 2.9^{\circ}, n=21\right)$ slightly lower than in antrum $\left(93.0^{\circ} \pm 3.2^{\circ}, n=17, p<0.05\right)$.

As shown in Figure 2, the contact angle on tissue derived from the body of stomach of adult rabbits $\left(36.1^{\circ} \pm 2.6^{\circ}\right)$ was lower than contact angles, measured by ADSA-CD. on the stomach body derived from both weanling $\left(84.2^{\circ} \pm 2.9^{\circ}\right)$ and suckling rabbits $\left(76.4^{\circ} \pm 2.7^{\circ}\right.$. ANOVA, $\left.p<0.05\right)$. There was no difference, however, between the contact angle values formed in antrum along the three age groups (ANOVA, $p>0.05$ ).

Surface tension of mucus. A time course evaluation of pendant drop shapes was performed with mucus prepared from the body of stomach. The start point of the mucus preparation would be projected to be near the value of the surface tension water (i.e. $72.58 \mathrm{~mJ} / \mathrm{m}^{2}$ ). However, as shown in Figure 3, over time the mucus solution influenced the interface between water and air. At the end point of the experiments $(3600 \mathrm{~s})$, the surface tension of mucus derived from the body of the stomach was

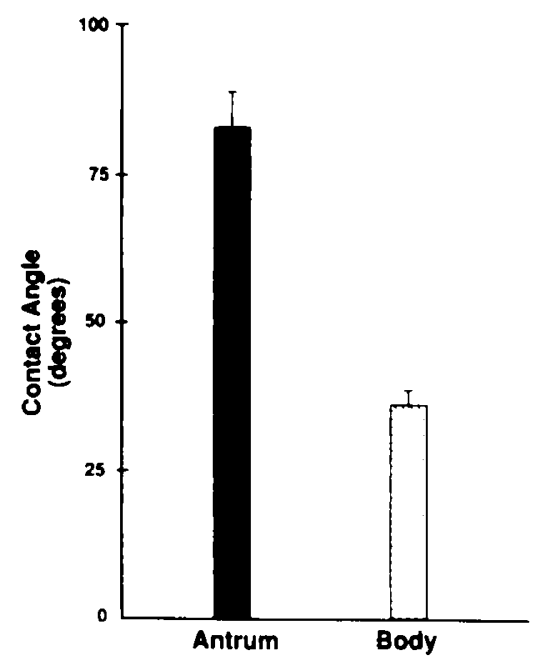

Fig. 1. Contact angles of water formed on segments of stomach from healthy adult rabbits. Results are expressed as mean \pm SEM. Contact angles formed in antral mucosa (solid har) were greater than those in body of stomach (hatched bar, $p=0.0001$ ). 


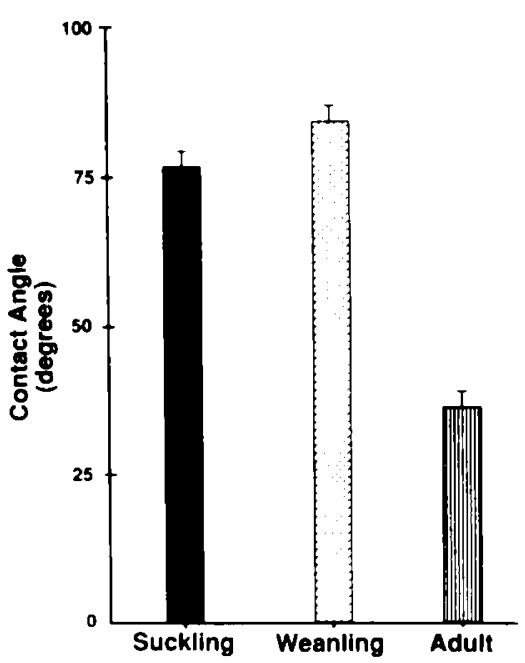

Fig. 2. Contact angles formed on mucosa of the body of the stomach from suckling rabbits (solid har), weanling rabbits (hatched har), and adult rabbits (vertical-lined har). Contact angles in adults were significantly smaller than those in the two younger age groups (ANOVA, $p<$ $0.05)$.

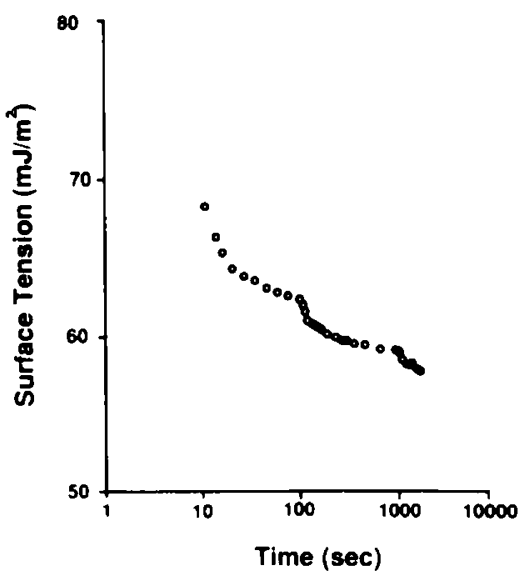

Fig. 3. Surface tension of soluble mucus $(1 \mathrm{mg} / \mathrm{mL})$ derived from the body of stomach of adult rabbits measured by ADSA of pendant drops at room temperature. A time course evaluation of pendant drops formed from three determinations is shown. Each value represents the mean for the drops. At the end point (i.e. $3600 \mathrm{~s}$ ), the surface tension of gastric mucus was $57.7 \mathrm{~mJ} / \mathrm{m}^{2}$.

$57.72 \pm 0.06 \mathrm{~mJ} / \mathrm{m}^{2}$. Surface tension is inversely correlated with hydrophobicity $(2,4)$. Therefore, this relatively high value of surface tension using pendant-drop shape analysis provides independent confirmation for results showing lower surface hydrophobicity in the body of stomach (as measured by a relatively low contact angle of water droplets formed on the surface mucosa). This surface tension value was greater than results obtained previously for mucus extracted from the distal ileum and colon of rabbits (4). Indeed, calculating the solid surface tension of the surface of the body of the stomach from the contact angle $\left(36.1^{\circ}\right)$ and the surface tension of the water droplet forming this contact angle $\left(72.5 \mathrm{~mJ} / \mathrm{m}^{2}\right)$ by means of an equation of state approach (25) yields a surface tension of $60.9 \mathrm{~mJ} / \mathrm{m}^{2}$, which is in good qualitative agreement with the above value.

\section{DISCUSSION}

These data show that there are regional differences in the surface hydrophobicity of stomach mucosa in the adult rabbit using the ADSA-CD technique to measure contact angles. Surface hydrophobicity in these experiments was determined by the
ADSA-CD and ADSA-MD techniques in which water droplets were placed onto the mucosal surface of the stomach. By using segments of tissue rather than biopsies. larger volumes of water droplets can be formed (4) and there are no crush artifacts, which can occur when using biopsy tissue that is only a few millimeters in diameter. Thus, surface properties can be more accurately determined and do not represent an overestimation of hydrophobic properties that can result when evaluating very small pieces of tissue.

The hydrophobic nature of the antrum could have important biologic implications, including, for example, affecting host susceptibility to infection with microbial pathogens $(26,27)$. Bacterial adhesion to epithelial cells is a multifactorial process that is mediated by both specific stereochemical interactions (e.g. receptor-ligand) and nonspecific interactions (e.g. hydrophobicity (1-3). In the human stomach. Helicohacter pylori primarily colonizes the antrum of the stomach (28). H. pylori and Helicobacter-like organisms have not been reported to colonize lapine stomach (29). However, in other animals including the ferret, related Helicobacter species infect both the antrum and the body of the stomach. A glycerolipid receptor for both Helicobacters has been identified (30) and shown to be present throughout the intestinal tract (31). This suggests that for infection to develop not only does the receptor have to be present but a favorable local microenvironment is required. Similar to other enteric bacterial pathogens (32), H. pylori is found both within the mucus layer overlying epithelial cells and underneath the mucus layer in close proximity to the mucosal epthelial cells $(33,34)$.

H. pylori strains were shown previously to demonstrate hydrophilic or hydrophobic surface properties depending on the assay conditions used $(35,36)$. Reduced surface hydrophobicity of the antrum occurs with $H$. pylori gastritis in humans (10). Reduced surface hydrophobicity in the antrum is not an inherent defect but, rather, secondary to the bacterial infection (12). In addition. lowered hydrophobicity has been observed previously with experimentally induced inflammation in the colon (4). Future studies will examine the effect of mucosal inflammation induced by exogenous ethanol or hydrochloric acid on surface hydrophobicity properties in the lapine stomach.

The findings presented herein also show that there are agerelated changes in the surface hydrophobicity of stomach body. Breast-fed animals had a significantly higher contact angle and. hence, higher surface hydrophobicity than adult rabbits. Agerelated differences in surface hydrophobicity were shown previously in different regions of the rabbit intestinal tract (4) and in the body of the rodent stomach (37). The effect of administering breast milk intragastrically to adult animals on hydrophobicity properties remains to be examined. In contrast with our findings in the rabbit stomach, increased surface hydrophobicity associated with advancing age was reported in the rat (38).

The higher levels of surface hydrophobicity in young animals might be influenced by dietary factors. For example, surfaceactive lipids in the milk contained in the diet of suckling rabbits could increase hydrophobic properties $(39,40)$. Reduced bile acids in the enterohepatic circulation of infants and a resulting reduction in gastric exposure to refluxed bile acids could also account for the increased hydrophobicity observed in the infant rabbits $(41,42)$.

Surface hydrophobicity of different regions of the stomach has been evaluated previously in other species. In humans, surface hydrophobicity measurements of the stomach have also been performed using mucosal biopsies taken through fiberoptic endoscopes. Unlike in animals, regional differences were not observed (10). Hills et al. (43) found that tissue from the oxyntic region of canine stomach was more hydrophobic than the antral mucosa. In contrast to the higher surface hydrophobicity of mucosa from the body of dog stomach, mucus from the same region was hydrophilic in nature (44). In the present study, a solution of mucus derived from the body of rabbit stomach was also hydrophilic in nature, as measured by the ADSA-P meth- 
odology. However, in contrast to the dog studies, this hydrophilic property of the mucus paralleled the relatively hydrophilic nature of the mucosal surface of the body of the rabbit stomach.

There are a number of possibilities that could account for varying results of surface hydrophobicity measurements in the stomach. One possibility is that the mucus layer is not present over the gastric epithelial cells. However, as we have shown previously (4), the methodology used to prepare the tissues for analysis does not remove the mucus layer overlying the mucosa. A second possibility is that the mucus layer is not responsible for the physical properties of the underlying epithelial cells. In other regions of the lapine gastrointestinal tract, the hydrophobic properties of the overlying mucus parallels the surface hydrophobicity properties (4). We, and others (43), have also found that it is difficult to mechanically remove adherent mucus from the underlying epithelial cells. Another possibility is that the methodology used by Hills et al. (44), which involved spreading mucus onto a hydrophobic surface, did not allow for an accurate determination of the effects of mucus in solution at the air-fluid interface.

The surface tension of soluble mucus presented in this study likely represents the hydrophobic properties of the surface of the stomach. Goddard et al. (45) showed that luminal mucus accounts for the surface hydrophobicity characteristics in canine stomach. We have presented findings to support the same conclusion in the lapine large intestine (4). In the stomach, phospholipids aligned on the luminal aspect of the surface mucus gel appear to account for these hydrophobic properties (46-52). Therefore, future studies will determine whether changes in either content or composition of phospholipids in mucus account for the ontogenic and regional changes in the surface hydrophobicity of the stomach that are described in this report (53).

\section{REFERENCES}

1. Beachey EH 1981 Bacterial adherence: adhesin-receptor interactions mediating the attachment of bacteria to mucosal surfaces. J Infect Dis 143:325-345

2. Magnusson KE 1989 Physiochemical properties of bacterial surfaces. Biochem Soc Trans 17:454-458

3. Busscher HJ, Weerkamp AH 1987 Specific and non-specific interactions in bacterial adhesion to solid substrata. FEBS Microbiol Rev 46:165-173

4. Mack DR. Neumann AW, Policova Z. Sherman PM 1992 Surface hydrophobicity of the intestinal tract. Am J Physiol 262:G171-G177

5. Peterson WL 1991 Helicobacter pilori and peptic ulcer disease. N Engl J Med 324:1043-1048

6. Rauws EAJ 1992 Role of Helicohacter pylori in duodenal ulcer. Drugs 44:921927

7. Sipponen P 1992 Helicobacter pylori infection: a common worldwide environmental risk factor for gastric cancer? Endoscopy 24:424-427

8. Cave DR, Vargas M 1989 Effect of a Campylobacter pylori protein on acid secretion by parietal cells. Lancet 2:187-189

9. Cave TR. Cave DR 1991 Helicobacter pylori stimulates pepsin secretion from isolated rabbit gastric glands. Scand J Gastroenterol 26(Suppl 181):9-14

10. Spychal RT, Marrero JM. Saverymuttu SH. Northfield TC 1989 Measurement of the surface hydrophobicity of human gastrointestinal mucosa. Gastroenterology 97:104-111

11. Spychal RT. Goggin PM, Marrero JM, Saverymuttu SH, Yu CW, Corbishley CM. Maxwell JD. Northfield TC 1990 Surface hydrophobicity of gastric mucosa in peptic ulcer disease. Relationship to gastritis and Campylohacter pylori infection. Gastroenterology 98:1250-1254

12. Goggin PM. Marrero JM. Spychal RT. Jackson PA. Corbishley CM. Northfield TC 1992 Surface hydrophobicity of gastric mucosa in Helicohacter pylori infection: effect of clearance and eradication. Gastroenterology 103:14861490

13. Neutra M, Forstner J 1987 Gastrointestinal mucus: synthesis, secretion, function. In: Johnson LR (ed) Physiology of the Gastrointestinal Tract, 2nd Ed. Raven Press. New York, pp 975-1008

14. Roberton AM. Mantle MM, Fahim REF, Specian RD. Bennick A, Kawagishi S, Sherman PM, Forstner J 1989 The putative "link" glycopeptide associated with mucus glycoproteins. Biochem J 261:637-647

15. Mack DR, Gaginella TS, Sherman PM 1992 Effect of colonic inflammation on mucin inhibition of Escherichia coli RDEC-1 binding in vitro. Gastroenterology 102:1199-1211

16. Lowry OH, Rosebrough NJ. Farr AL, Randall RJ 1951 Protein measurement with the Folin phenol reagent. J Biol Chem 193:265-275

17. Duncan-Hewitt WC, Policova Z. Cheng P, Vargha-Butler EI, Neumann AW
1989 Semiautomatic measurement of contact angles on cell layers by a modified axisymmetric drop shape analysis. Colloids Surfaces 42:391-403

18. Skinner FK, Rotenberg Y, Neumann AW 1989 Contact angle measurement from the contact diameter of sessile drops by means of a modified axisymmetric drop shape analysis. J Colloid interface Sci 1.30:25-34

19. Neumann AW, Good RJ 1979 Techniques of measuring contact angles. In: Good RJ. Stromberg RR (eds) Surface and Colloid Science. II. Experimental Methods. Plenum, New York. pp 31-39

20. Drumm B, Neumann AW, Policova Z. Sherman PM 1989 Bacterial cell surface hydrophobicity properties in the mediation of in vitro adhesion by the rabbit enteric pathogen Excherichia coli strain RDEC-1. J Clin Invest 84:15881594

21. Cheng P, Li D. Boruvka L, Rotenberg Y. Neumann AW 1990 Automation of axisymmetric drop shape analysis for measurement of interfacial tensions and contact angles. Colloids Surfaces 43:151-167

22. Rotenberg Y, Boruvka L. Newmann AW 1983 Determination of surface tension and contact angle from the shapes of axisymmetric fluid surfaces. J Colloid Interface Sci 93:169-183

23. Moy E. Cheng P. Policova Z. Treppo S. Kwok D. Mack DR. Sherman PM. Neumann AW 1991 Measurement of contact angles from the maximum diameter of non-wetting drops by means of a modified axisymmetric drop shape analysis. Colloids Surfaces 58:215-227

24. Winer BJ 1971 Statistical Principles in Experimental Design. McGraw-Hill. New York

25. Li D. Neumann AW 1992 Contact angles on hydrophobic solid surfaces and their interpretation. J Colloid Interface Sci 148:190-200

26. van Loosdrecht MCM. Lyklema J. Norde W. Schraa G, Zehnder AJB 1987 The role of bacterial cell wall hydrophobicity in adhesion. Appl Environ Microbiol 53:1893-1897

27. Jacobson SH, Tullus K. Brauner A 1989 Hydrophobic properties of Escherichia coli causing acute pyelonephritis. J Infect 19:17-23

28. Drumm B. Sherman PM. Cutz E. Karmali M 1987 Association of Campylehacter pylori on the gastric mucosa with antral gastritis in children. $\mathrm{N}$ Engl J Med 316:1557-1561

29. Fox JG. Lee A 1989 Gastric campylobacter-like organisms: their role in gastric disease in laboratory animals. Lab Anim Sci 39:543-553

30. Gold BD. Huesca M. Sherman PM. Lingwood CA 1993 Helicohacter mustelae and Helicohacter pylori bind to common lipid receptors in virro. Infect Immun 61:2632-2638

31. Gold B. Dytoc M. Huesca M. Philpott D. Lingwood C, Czinn S, Sherman PM 1993 Comparison of Helicohacter mustelae and H. pylori adhesion in vitro and in vivo. Abstracts of the annual meeting of the American Society of Microbiology (abstr B52)

32. Sherman PM, Boedeker EC 1987 Pilus-mediated interactions of the Escherichia coli strain RDEC-1 with mucosal glycoproteins in the small intestine of rabbits. Gastroenterology 93:734-743

33. Tricottet V. Bruneval P. Vire O. Camilleri JP. Bloch F. Bonte N, Roge J 1986 Campylobacter-like organisms and surface epithelium abnormalities in active chronic gastritis in humans: an ultrastructural study. Ultrastructr Pathol 10:113-122

34. Dytoc M. Gold B. Louie M. Huesca M. Fedorko L. Crowe S. Lingwood C. Brunton J. Sherman PM 1993 Comparison of Helicohacter pylori and attaching-effacing Escherichia coli adhesion to eukaryotic cells. Infect Immun 61:448-456

35. Smith JI. Drumm B. Neumann AW. Policova Z. Sherman PM 1990 In vitro surface properties of the newly recognized gastric pathogen Helicohacter pylori. Infect Immun 58:3056-3060

36. Pruul H, Goodwin CS, McDonald PJ. Lewis G. Pankhurst D 1990 Hydrophobic characterization of Helicohacter ( Campylohacter) py:tori. J Med Microbiol $32: 93-100$

37. Dial EJ. Lichtenberger LM 1988 Surface hydrophobicity of the gastric mucosa in the developing rat. Effects of corticosteroids, thyroxine, and prostaglandin E2. Gastroenterology 94:57-61

38. Dial EJ, Lichtenberger LM 1989 Development of the gastric barrier to acid. In: Lebenthal E (ed) Human Gastrointestinal Development. Raven Press. New York, pp 353-363

39. Dial EJ. Lichtenberger LM 1987 Milk protection against experimental ulcerogenesis in rats. Dig Dis Sci 32:1145-1150

40. Dial EJ. Lichtenterger LM 1984 A role for milk phospholipids in protection against gastric acid. Studies in adult and suckling rats. Gastroenterology 87:379-385

41. Spychal RT, Savalgi RS, Marrero JM. Saverymuttu SH, Kirkham JS, North field TC 1990 Thermodynamic effects of bile acids in the stomach. Gastroenterology 99:305-310

42. Goggin PM, Northfield TC. Spychal RT 1991 Factors affecting gastric mucosal hydrophobicity in man. Scand J Gastroenterol 26(Suppl 181):65-73

43. Hills BA, Butler BD, Lichtenberger LM 1983 Gastric mucosal barrier: hydrophobic lining to the lumen of the stomach. Am J Physiol 244:G561-G568

44. Hills BA 1985 Gastric mucosal barrier: stabilization of hydrophobic lining to the stomach by mucus. Am J Physiol 249:G342-G349

45. Goddard PJ, Kao Y-CJ. Lichtenberger LM 1990 Luminal surface hydropho- 
bicity of canine gastric mucosa is dependent on a surface mucous gel. Gastroenterology 98:361-370

46. Lichtenberger LM 1987 Membranes and barriers: with a focus on the gastric mucosal barrier. Clin Invest Med 10:181-188

47. Hills BA, Kirwood CA 1992 Gastric mucosal barrier: barrier to hydrogen ions imparted by gastric surfactant in vitro. Gut 33:1039-1041

48. Kao Y-CJ. Lichtenberger LM 1991 Phospholipid- and neutral lipid-containing organelles of rat gastroduodenal mucous cells. Possible origin of the hydrophobic mucosal lining. Gastroenterology 101:7-21

49. Lichtenberger LM. Romero JJ, Kao Y.CJ, Dial EJ 1990 Gastric protective activity of mixtures of saturated polar and neutral lipids in rats. Gastroenterology $99: 311-326$
50. Kao Y-CJ. Goddard PJ, Lichtenberger LM 1990 Morphological effects of aspirin and prostaglandin on the canine gastric mucosal surface. Analysis with a phospholipid-selective cytochemical stain. Gastroenterology 98:592606

51. Hills BA, Kirwood CA 1989 Surfactant approach to the gastric mucosal barrier: protection of rats by banana even when acidified. Gastroenterology 97:294303

52. Sbarbati A, Deganello A. Tamassia G. Bertini M. Gaburro D, Osculati F 1992 Surfactant-like material in the antral gastric mucosa of children. J Pediatr Gastroenterol Nutr 15:279-284

53. Schmitz MGJ. Renooij W 1990 Phospholipids from rat, human, and canine gastric mucosa. Composition and metabolism of molecular classes of phosphatidylcholine. Gastroenterology 99:1292-1296 